\title{
CLINICAL CASE OF THE MULTIMODAL SCHEME USING FOR LIMBS AND FRONTAL THORAX SOFT TISSUES RECONSTRUCTION
}

\author{
I. P. Khomenko ${ }^{1}$, K. V. Gumenuk ${ }^{1}$, S. O. Korol, Ye. V. Tsema ${ }^{1,2}$, R. N. Mikhaylusov ${ }^{3}$, \\ S. V. Tertyshnyi, O. M. Popova ${ }^{5}$, P. P. Yermuraki ${ }^{6}$ \\ ${ }^{I}$ National Military Medical Clinical Center of the Ministry of Defense of Ukraine, Kyiv City, Ukraine \\ ${ }^{2}$ Bogomolets National Medical University, Ukraine \\ ${ }^{3}$ Kharkiv Medical Academy of Postgraduate Education, Ukraine, Kharkiv City \\ ${ }^{4}$ Military Medical Clinical Center of the Southern Region, Ministry of Defense, Ukraine, Odesa City \\ ${ }^{5}$ Military Medical Clinical Center of the Eastern Region, Ministry of Defense, Ukraine, Dnipro City \\ ${ }^{6}$ Odessa National Medical University, Ukraine, Odesa City
}

DOI: https://doi.org/10.31435/rsglobal_conf/30112020/7269

\begin{abstract}
Gunshot wounds of soft tissues are often accompanied by bulky tissue defects that require reconstructive surgery in order to quickly and maximally restore the anatomical and functional integrity of the anatomical area. In the course of the analysis of wounds and preparation for reconstructive closure of gunshot defects of soft tissues, it is essential to identify areas of damage and preserve the sources of perfusion of areas of "future reconstruction". Current experience and results of treatment of gunshot wounds of soft tissues show that this goal can be achieved by the sequential performance - dynamic infrared spectral thermography in combination with the Doppler method of examination of the vascular network of the damaged anatomical structure.
\end{abstract}

Keywords: soft-tissue defect, reconstruction, Key-Stone, gunshot wound, spectral thermography, Doppler.

Introduction. During the military conflict in Eastern Ukraine, considerable experience has been gained in providing medical care to the wounded and injured with soft tissue defects. In order to use the full potential of the trophic capabilities of the moving tissues, it is essential to identify and maintain a dominant power supply during the operation. Restoration of the damaged structure, function, maximum cosmetic effect as a result of surgical reconstruction is possible only under the condition of tactically correctly planned and "ideally" [4] performed surgical intervention or staged surgical interventions.

Gunshot wounds of soft tissues are often accompanied by bulky tissue defects that require reconstructive surgery in order to quickly and maximally restore the anatomical and functional integrity of the anatomical area [2]. In the course of the analysis of wounds and preparation for reconstructive closure of gunshot defects of soft tissues, it is essential to identify areas of damage and preserve the sources of perfusion of areas of "future reconstruction" [6]. Current experience and results of treatment of gunshot wounds of soft tissues show that this goal can be achieved by the sequential performance - dynamic infrared spectral thermography in combination with the Doppler method of examination of the vascular network of the damaged anatomical structure $[1,5,7,8]$.

Soft tissue defects of gunshot etiology differ in several signs, which determine the peculiarities of the pathological process. The optimality of the reconstruction method depends on the ability to integrally assess the features of the tissue defect in each case, taking into account systemic disorders and individual characteristics of the human macroorganism, which in turn depends on the experience of the surgeon. Rationalization and simplification of the process of preoperative planning, intra- and postoperative dynamic control are among the tasks that provide the opportunity to "maximally" restore the damaged area [4]. A representative clinical case in the process of surgical reconstruction of gunshot defects of the soft tissues of the extremities and anterior surface of the chest during the use of a multimodal scheme in pre-, intra- and postoperative monitoring is described below.

Clinical case. Wounded $\mathrm{X}$ was hospitalized to the Clinic of Reconstructive Surgery and Thermal Injuries of the South Region Military Medical Clinical Center on May 3, 2018, with 
complaints of wounds in the chest, right forearm, left hand, left leg, accompanied by severe pain, severe pain, decreased vision in the right eye, lack of vision in the left eye.

During the collection of anamnesis it was established that on April 23, 2018, during the execution of a combat mission in the anti-terrorist operation zone for demining the area near the settlement of Granite around 12:00 the patient received an explosive wound due to a mine explosion. First aid was provided on the spot by soldiers of the unit. He was transported by ambulance to the Volnovakha Central Regional Hospital, where he received qualified medical care in the amount of PST of gunshot wounds and correction of hypovolemia. 23.04.18 at 20:00 the patient got evacuated to Dnipro by air, hospitalized in RCH named after I.I. Mechnikov, where repeated staged surgical treatments of gunshot wounds were performed. For further treatment on May 3, 2018 the patient was airlifted to Military Medical Clinical Center of the Southern Region and hospitalized in the department of surgical infections.

Objective status at the time of hospitalization: Body temperature $37.5^{\circ} \mathrm{C}$. Height $-180 \mathrm{~cm}$, weight $-110 \mathrm{~kg}$. The patient's condition is moderate, stable. Consciousness is clear, the reaction to the environment is adequate, the orientation in time, space and self is preserved. Meningeal symptoms are negative. The skin, visible mucous membranes are clean, pale pink, moist and warm to the touch. Peripheral lymph nodes are not enlarged. Auscultatory: in the lungs above the entire surface of the lung tissue there is vesicular respiration, no wheezing. RR equals 17 per minute. The activity of the heart is rhythmic, heart tones are clear, without pathological noises. Blood pressure equals $120 / 80 \mathrm{~mm}$ $\mathrm{Hg}$, pulse 72 per minute. The tongue is clean and moist. The abdomen is soft, symmetrical, not enlarged, evenly participates in the act of breathing. Deep palpation is painless throughout. There are no symptoms of peritoneal irritation. Peristalsis is active, uniform. The liver is not enlarged. Kidneys, the spleen is not palpable. The tapping symptom is negative on both sides. The bladder is not reliably determined by palpation and percussion over the womb. Active peristalsis is determined over the entire surface of the abdomen.

St. localis: The transparency of the sclera of the left eye is significantly reduced, there is no vision. The skin of the face is pale pink, above the upper lip on the left there is a sutured postoperative wound measuring $1.5 \times 0.5 \mathrm{~cm}$ without signs of inflammation. In the area of the anterior surface of the thorax in the projection of the xiphoid condyle there is a sluggish wound, measuring $7.0 \mathrm{x} 8.0 \mathrm{x}-0.7 \mathrm{~cm}$, irregular in shape with uneven, hyperemic, swollen edges, pronounced paravular edema, partially covered with immature gray-white granulations, upon touching the wound surface there is bleeding. Palpation along the contour of the wound is painful. In the area of the 5th intercostal space on the right along the anterior inguinal line there is a granular wound $2.5 \times 3.0 \times 0.6 \mathrm{~cm}$ with jagged edges, moderate paravular infiltrative edema, the bottom of the wound is partially covered with gray fibrin, upon touching the wound surface with an instrument the bleeding is absent. In the area of the anterior abdominal wall, multiple wounds 0.3 to $1.5 \mathrm{~cm}$ in diameter are identified, the surrounding soft tissues covered with a black scab are infiltrated with a bluish color. Under the navel there is a postoperative wound (paracentesis), the edges of the wound are adapted, without signs of inflammation. The contours of the right forearm are deformed due to interstitial edema of soft tissues and wounds on the flexor surface measuring $10.0 \times 6.0 \times 2.5 \mathrm{~cm}$, irregular in shape with uneven, swollen edges of blue-purple color, pronounced paravular edema, partially covered with a layer of gray fibrin, partially scab black, with moderate serous-mucous secretions from the surface. On the outer surface there is a wound of longitudinal shape measuring $4.0 \times 0.5 \mathrm{~cm}$, the sutures are adapted, without signs of inflammation. The contours of the left hand are deformed due to interstitial edema of soft tissues, the skin is hyperemic, on the palmar surface with the transition to the lateral surface of the hand there is a wound with a soft tissue defect, size $6.0 \times 5.0 \times 0.6 \mathrm{~cm}$ sharply painful on palpation, covered with layers of gray fibrin. In the area of the main phalanx of the first finger and tenor there are wounds with a soft tissue defect, covered with a layer of gray-white fibrin, measuring $1.5 \times 1.0 \times 0.5 \mathrm{~cm}$ and $3 \times 2 \times 0.5 \mathrm{~cm}$. There is no bleeding on contact with the wound surface. In the area of the right half of the scrotum there is a wound of irregular shape, with uneven edges, size $3.0 \times 1.5 \times 0.4 \mathrm{~cm}$ painful on palpation, does not bleed when touched. On the anterior surface of the left leg there is an NPWT system functioning in pulse mode with indicators of $-125 \mathrm{mmHg}$. The vacuum is stable.

Clinical diagnosis: Explosive injury (23.04.18). CTBI. $1^{\text {st }}$ degree concussion. Shrapnel blind injuries to the soft tissues of the face and head. Gunshot shrapnel wounds to both eyes. Contusion, OU subconjunctival hemorrhage, penetrating injury of the left eye. Multiple gunshot wounds to the anterior surface of the chest, the anterior surface of the abdomen. Multiple shrapnel blind injuries to the right 
forearm, left hand with a soft tissue defect. Multiple gunshot shrapnel blind injuries of the anterior and inner surface of the right thigh, scrotum, anterior surface of the left leg. Condition after operations (23.04.18): laparocentesis; (24.04.18): removal of foreign bodies of the cornea and conjunctiva, revision of the OS sclera, vitriolectomy and tamponade of the vitral cavity with a gas mixture, sclera wound PTS and removal of foreign bodies of the OD cornea; (28.04.18): necrectomy, debridement of shrapnel wounds of the right forearm, left hand, left leg, right thigh, installation of NPWT system. (02.05.18): repeated surgical treatment of gunshot wounds of both upper extremities, imposition of secondary sutures.

The clinical task for the reconstruction of gunshot defects of soft tissues was available in the wounded soft tissue defects on the anterior surface of the chest, right forearm, shins which according to the proposed classification refers to soft tissue defects of these localizations, simple topographic and anatomical structure, complex histological structure, large in area, medium in volume, divergent relative to the tension lines, geometrically irregular, local, thermostable by IR spectrographic indicators.

As the first stage of reconstruction, stage treatment of wound surfaces of defects of the anterior chest, flexor surface of the right forearm, anterior surface of the middle third of the left leg by physical-chemical and mechanical methods (ultrasonic cavitation, NPWT systems, applications with solutions of betadine and decasanide, repeat wound detritus) was conducted for 5 days.

Photos before the operation.

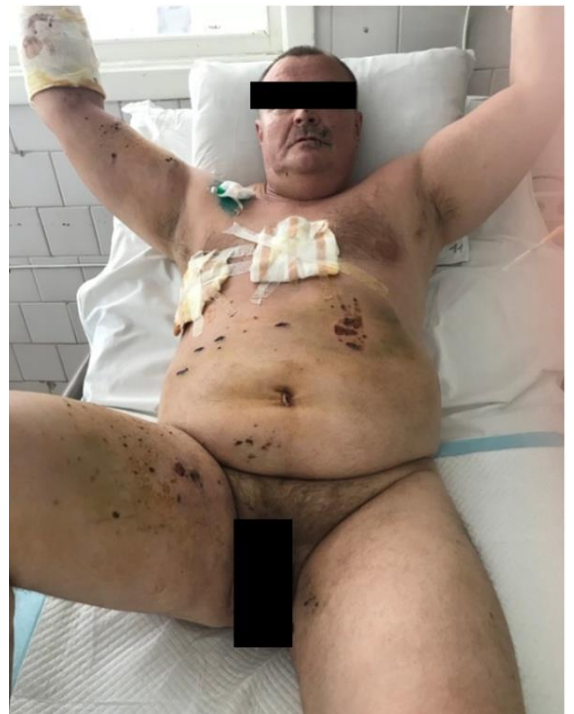

Fig.1. View of the wounded on admission, day 1 in the department of surgical infections Military Medical Clinical Centre of the Southern Region (10 days after the wound).

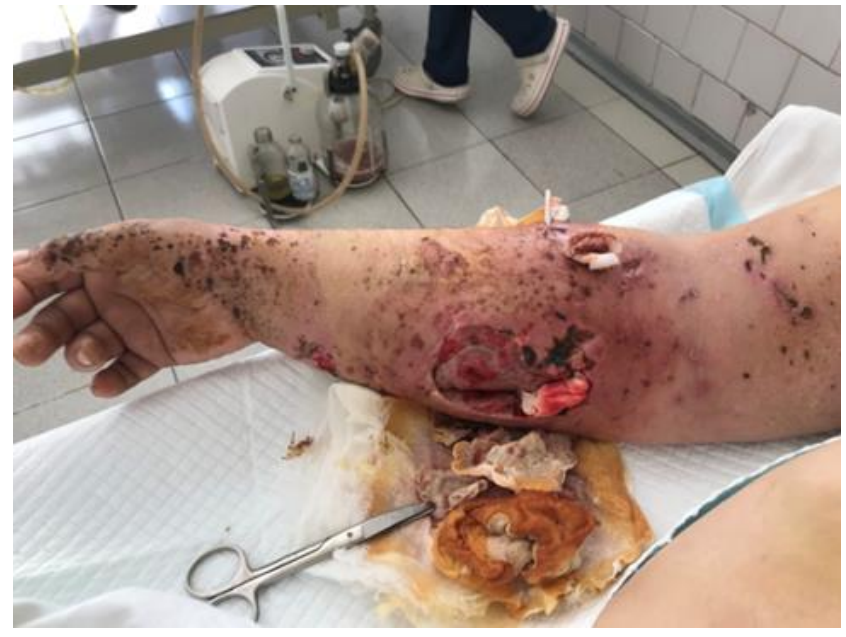

Fig.2. View of the flexion surface of the right forearm on admission, day 1 in the department of surgical infections Military Medical Clinical Centre of the Southern Region (10 days after the wound).

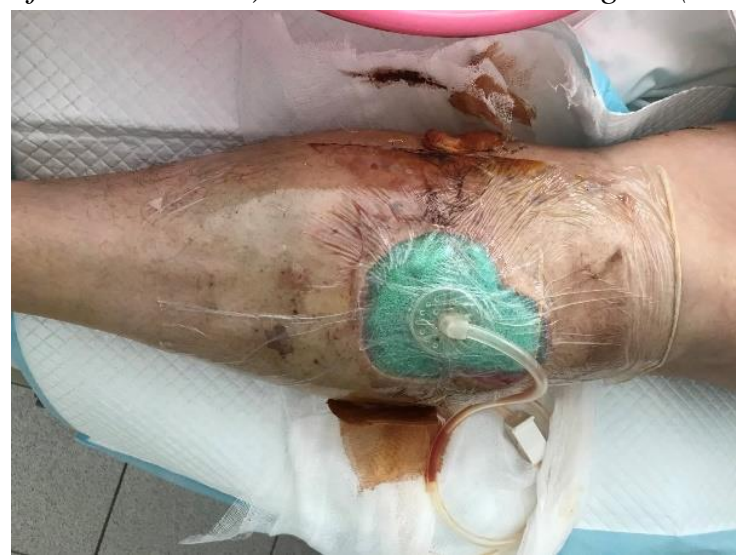

Fig.3. View of the postoperative wound of the anterior surface of the left leg, on admission, day 1 in the department of surgical infections Military Medical Clinical Centre of the Southern Region (with NPWT system) 
Preoperative dynamic monitoring was performed for 5 days and zones of thermographic stability with Doppler confirmation of satisfactory blood flow were established:

1. On the anterior surface of the chest during the dynamic digital thermography of the wound surface and surrounding tissues the temperature of $+32.5^{\circ} \mathrm{C}$, blood flow rate of $10 \mathrm{~cm} / \mathrm{s}$ was measured, the reconstruction by the full-layer flap Keystone method with "power switches" in the form of perforating vessels from a. thoracica interna (rami intercostales 5-6) was planned.

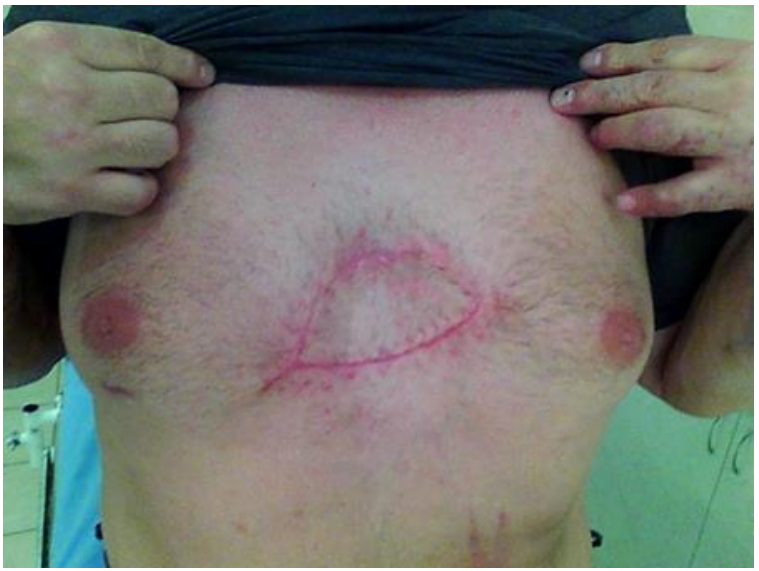

Fig.4. View of the anterior surface of the thorax 1 month after discharge from the hospital.

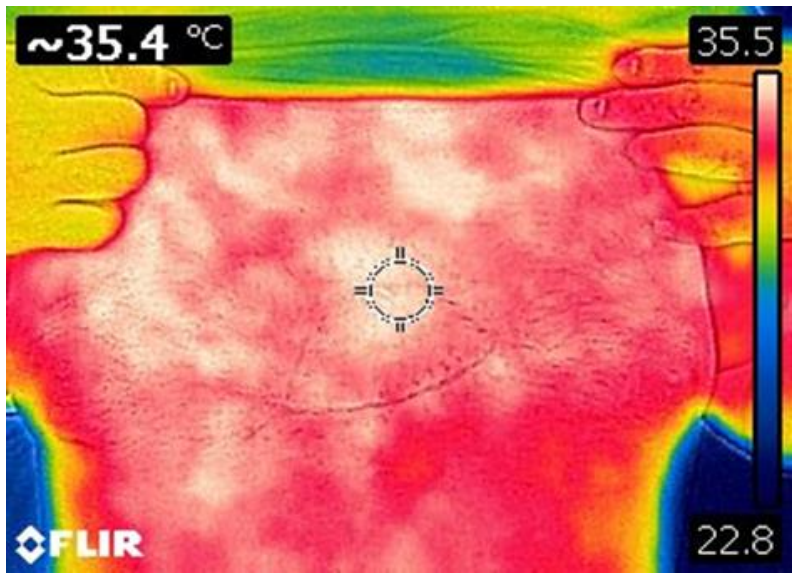

Fig.5. Dynamic digital thermography of the anterior surface of the chest 1 month after discharge from the hospital. The pre-identified 5 perforating vessels of the anterior surface of the chest are shown by dotted arrows.

2. On the flexor surface of the middle third of the right forearm during the dynamic digital thermography of the wound surface and surrounding tissues the temperature of $+32.1^{\circ} \mathrm{C}$, blood flow rate of $9 \mathrm{~cm} / \mathrm{s}$ was measured, the reconstruction by the Keystone method of double rotary flaps with "power switches" in the form of $a$. radialis dexter (rami medialis) and a. ulnaris dexter (rami distalis) perforating vessels was planned.

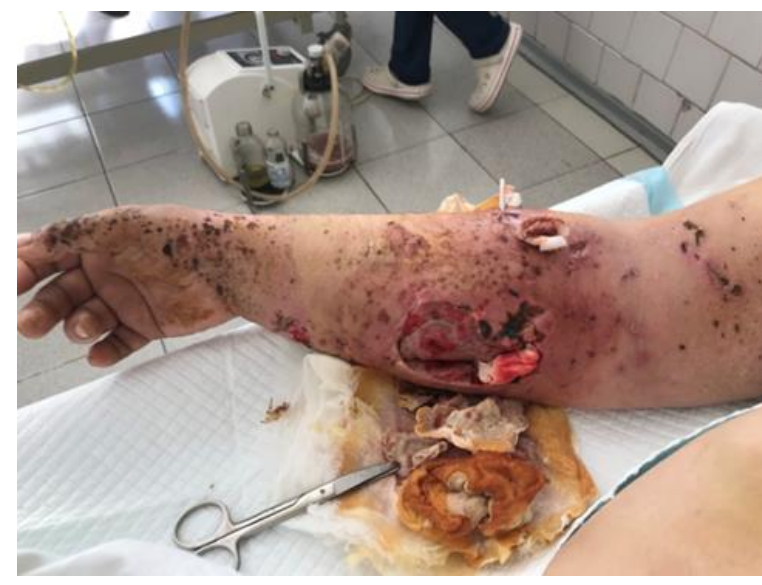

Fig.6. View of the flexor surface of the right forearm on admission, day 1 in the department of surgical infections Military Medical Clinical Centre of the South Region.

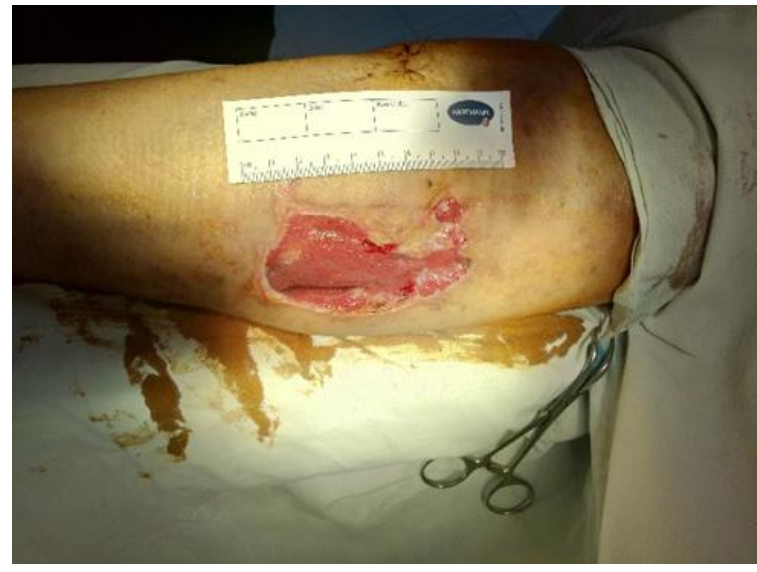

Fig.7. View of the flexor surface of the right forearm after complex surgical treatment in the department of surgical infections Military Medical Clinical Centre of the South Region (5 days of hospitalization). 


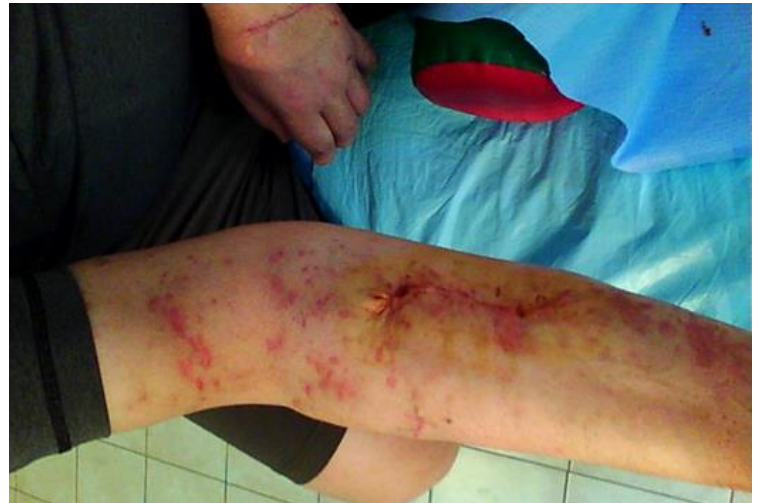

Fig.8. View of the flexor surface of the right forearm 14 days after surgery by the double rotary flaps method.

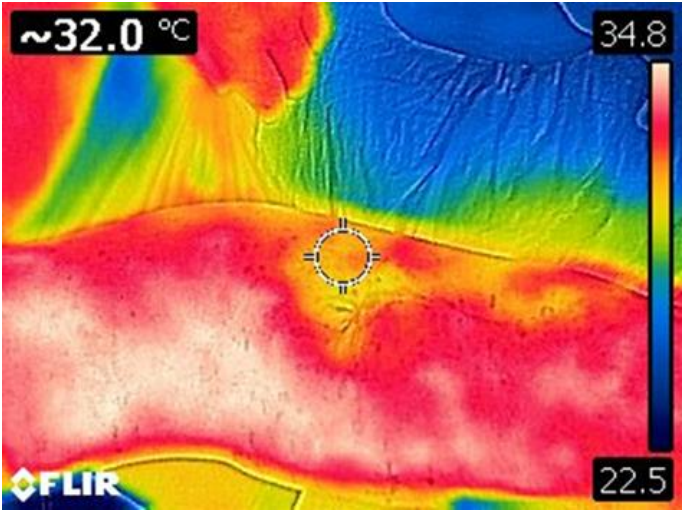

Fig.9. Thermographic view of the flexor surface of the right forearm after reconstruction by the method of double rotary flaps (21 days of hospitalization).

3. On the anterior surface of the middle third of the left leg during the dynamic digital thermography of the wound surface and surrounding tissues the temperature of $+31.5^{\circ} \mathrm{C}$, blood flow rate of $6 \mathrm{~cm} / \mathrm{s}$ was measured, the reconstruction by the method of a full-layer flap by the Keystone method with "power switches" in form of a. tibialis anterior sinister (rami medialis) et a. sinus fibularis (rami medialis).

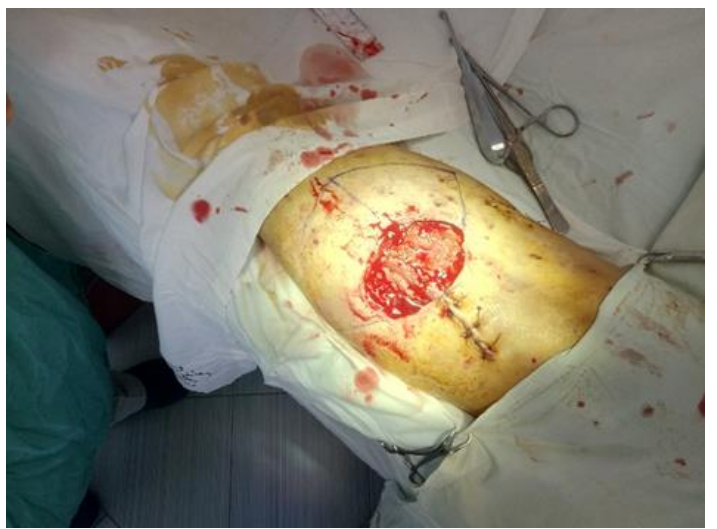

Fig.10. Marking of the future flap on the front surface of the middle third of the left leg by the Keystone method ( 9 days of inpatient treatment, 19 days from the date of injury).

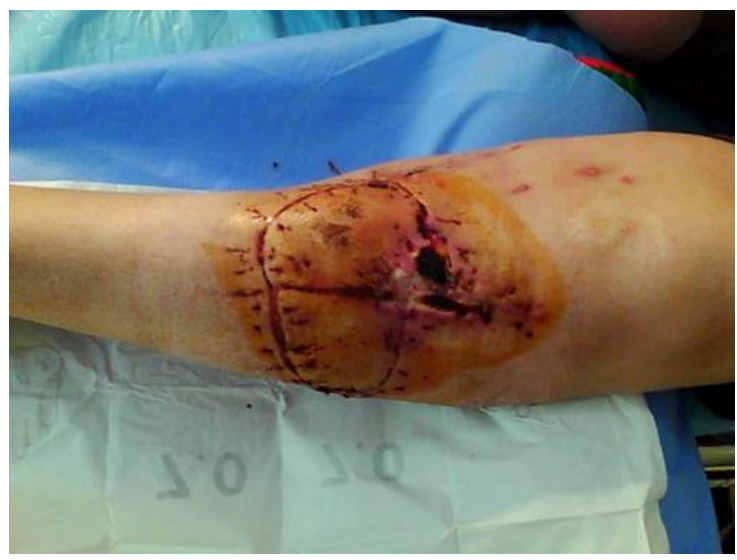

Fig.12. Partial tissue necrosis along the upper pole of the postoperative wound of the anterior surface of the middle third of the left leg

(23 days of inpatient treatment, 33 days from the moment of injury).

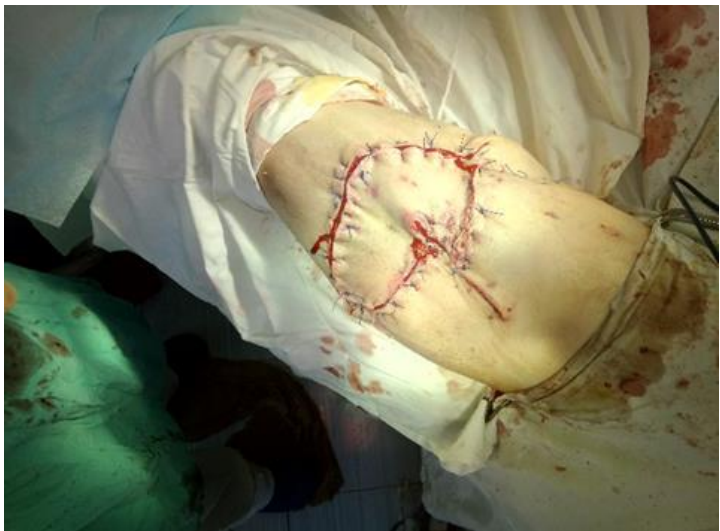

Fig.11. Type of postoperative wound.

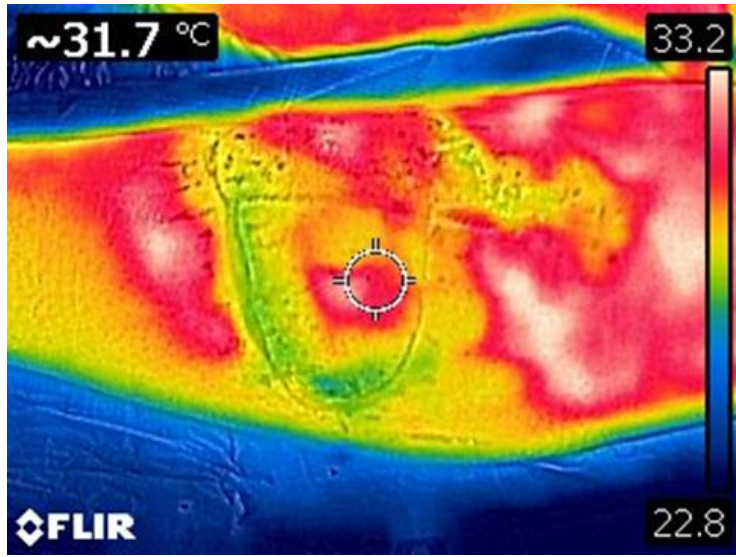

Fig.13. Thermographic view of the postoperative wound of the anterior surface of the middle third of the left leg (23 days of inpatient treatment, 33 days from the time of injury). 
Discussion. The use of a multimodal scheme during the surgical reconstruction of gunshot defects of soft tissues allows to provide quality care to the wounded and injured in the area of environmental protection with a clearly formed doctrine at all stages in the Ukrainian Navy.

According to the results of the clinical case, compliance with the proposed multimodal algorithm and monitoring of the victim with a gunshot defect of soft tissues provides high-quality surgical reconstruction. With this result, it is possible to say that most of the wounded with soft tissue defects in the subsequent postoperative period will belong to the category of lightly wounded with the optimal prospect of a rapid return to service $[4,9]$.

The method of dynamic monitoring can be used at all levels of medical care in the Ukrainian Navy, but taking into account time, conditions, material base, the level of specialists of the medical institution, the multimodal scheme provides maximum anatomical-functional result of surgical reconstruction at the IV level [3].

Conclusions. Consistent application of methods of dynamic digital thermography and Doppler scanning of vessels promotes adequate differentiation of dominant zones and sources of alternative blood supply.

The fundamental factors in the process of preoperative modeling of donor flaps are the indicators of thermographic diagnostics of more than $32^{\circ} \mathrm{C}$ and the results of audio-examination of perforating vessels ("power switches") with indicators of speed and volume of blood flow (according to the anatomical part of the human body).

The use of affordable and effective techniques in the process of reconstructive surgery allows achieving good anatomical-functional and cosmetic results of reconstructive interventions with high probability.

\section{REFERENCES}

1. Hallock G. Doppler sonography andcolor duplex imaging forp lanning a perforator flap // ClinPlastSurg. 2003. - Vol.30. - P.347-357.

2. Kashtalyan M.A. Modern methods of gunshot wounds treating / M.A. Kashtalyan, O.S. Gerasimenko, V.Yu. Shapovalov [et al.] // Hospital Surgery. - 2015. - N1. - P. 126 [In Ukrainian].

3. Khomenko I.P. Characteristics of combat surgical trauma, shortcomings and achievements in the treatment of wounded and injured in the conditions of anti-terrorist operation / I.P. Khomenko, A.V. Verba, Ye.M. Khoroshun // Science and Practice. - 2016. - N 1-2. - C. 27-31 [In Ukrainian].

4. Korol S.O. Gunshot and mine injuries in the system of assistance to the wounded during the anti-terrorist operation // Abstr. of the XVII Congress of orthopedists-traumatologists of Ukraine. - Kyiv, 2016. - P. 27 28 [In Ukrainian].

5. Pinter L. Uber die Bewertung des thermographischen Bildes / L. Pinter // Klin. Monatsbl. Augenheilkd. 2010 - Vol. 196, N 5. - P. 402-404.

6. Slesarenko S.V. Preoperative location of perforating arteries using infrared thermography / S.V. Slesarenko, P.A. Badyul, K.S. Slesarenko // Reconstr. Plastic Surgery Issues. - 2016. - N 1(56). - P. $13-19$ [In Russian].

7. Remote infrared thermography as a modern non-invasive method for diagnosing diseases / L.G. Rosenfeld, A.V. Samokhin, A.F. Venger [et al.] // Ukr. Med. J. - 2008. - Vol. 11-12I, N 6 (68). - P. $92-97$ [In Russian].

8. Voloshin G.G. Thermal structure of the skin in healthy individuals / ПюПю Voloshin // Med. Business. 2012. - Vol. 41. - P. 20-24 [In Ukrainian].

9. Zarutsky Ya.L. Optimization of staged surgical treatment of the wounded on the basis of metric classification of soft tissue defects / Ya.L. Zarutsky, I.B. Plis, S.O. Korol, A.O. Kompaniets // Clin. Surgery. - 2018. - N 2(85). P. 77-80 [In Ukrainian]. 